\title{
Discursos do profissionalismo docente paradoxos e alternativas conceptuais*
}

\author{
MARIA ASSUNÇÃO FLORES \\ Universidade do Minho, Braga, Portugal
}

\section{RESUMO}

Neste texto procuramos identificar e analisar os discursos do profissionalismo docente por meio de distintas concepções, características e dimensões. Para tal, convocam-se os autores que mais se têm dedicado a essa temática no panorama internacional. Defende-se, assim, que a análise do profissionalismo docente no quadro atual implica a consideração dos múltiplos discursos que têm emergido nesse domínio, sobretudo aqueles que se associam às chamadas "culturas de performatividade" e de prestação de contas, no intuito de desvelar as implicações (e as contradições) que lhes estão subjacentes, com repercussões nas identidades profissionais dos professores.

\section{PALAVRAS-CHAVE}

profissionalismo docente; trabalho docente; identidades profissionais.

* Este texto parte de reflexões escritas da autora e foi desenvolvido no contexto da revisão da literatura no âmbito do projeto intitulado "Teachers Excercising Leadership" (2011-2013), financiado pelo Fundo Europeu de Desenvolvimento Regional (FEDER), por meio do Programa Operacional Factores de Competitividade (COMPETE) e por fundos nacionais pela Fundação para a Ciência e a Tecnologia (FCT) (PTDC/ CPE-CED/112164/2009). 


\title{
DISCOURSES ABOUT TEACHER PROFESSIONALISM: PARADOXES AND CONCEPTUAL ALTERNATIVES
}

\begin{abstract}
This paper identifies and analyses discourses about teacher professionalism based upon different conceptions, characteristics and dimensions. For that, the most important authors in this field are discussed in an international context. It is argued that the analysis of teacher professionalism at present implies the consideration of multiple discourses that have emerged in this field. In particular the paper looks at the discourses related to the so-called "performance cultures" and accountability, in order to unveil the implications (and contradictions) underpinning them with repercussion for teachers' professional identities.
\end{abstract}

\section{KEYWORDS}

teacher professionalism; teachers' work; professional identities.

\section{DISCURSOS DE LA PROFESIONALIDAD DE LOS DOCENTES: PARADOJAS Y ALTERNATIVAS CONCEPTUALES}

\section{RESUMEN}

En este trabajo se tratará de identificar y de analizar los discursos de la profesionalidad de los docentes por medio de distintos conceptos, características y dimensiones. Para ello, se convocan a los autores que más se han dedicado a este tema en el ámbito internacional. Se argumenta, por tanto, que el análisis de la profesionalidad de los docentes en el marco actual implica la consideración de los múltiples discursos que han surgido en este campo, especialmente aquellos asociados a las llamadas "culturas de la performatividad" y de rendición de cuentas, en el sentido de dar a conocer las implicaciones (y las contradicciones) que les son subyacentes, con impacto en las identidades profesionales de los docentes.

PALABRAS CLAVE

profesionalidad docente; enseñanza; identidades profesionales. 


\section{INTRODUÇÃO}

O entendimento sobre o que significa ser professor, que se manifesta quer no quadro legal e curricular, quer nos modos de ser e de estar na profissão, assenta em perspetivas distintas de encarar o papel dos docentes no desenvolvimento do currículo e as suas funções no contexto da escola e do sistema educativo, com repercussões no modo de entender sua formação e avaliação. Gewirtz et al. (2009a) chamam atenção para as mudanças sociais, culturais e políticas que têm tido repercussões no trabalho dos professores, nomeadamente um maior ceticismo em relação à sua autoridade, uma cultura consumista e transformações nas tecnologias de informação e comunicação, entre outros aspetos. Apesar disso, os mesmos autores salientam que os professores têm respondido de diferentes modos a esses desafios em diversos contextos, com implicações ao nível do profissionalismo docente e das suas identidades profissionais.

As identidades profissionais dos professores - quem são, a imagem que têm de si próprios, os sentidos que atribuem ao seu trabalho e a si próprios enquanto professores e os significados que os outros thes atribuem - dependem de uma diversidade de fatores: da forma como se relacionam com seus alunos, da disciplina que ensinam, dos papéis que desempenham, dos contextos em que trabalham, do quadro social e cultural mais amplo em que o ensino se inscreve, da sua biografia, das oportunidades de aprendizagem e de desenvolvimento profissional no local de trabalho, do apoio etc.

A literatura mais recente nesse âmbito inclui a análise de um conjunto diversificado de dimensões inerentes ao trabalho docente e ao modo como ele é perspetivado num dado momento e num determinado contexto, no sentido de compreender o modo como os professores vivem a mudança no seu quotidiano profissional, sobretudo quando ela implica alterações profundas, ligadas, entre outros aspetos, ao estatuto da carreira docente e à avaliação do desempenho docente, como acontece no caso português, mas também noutros contextos. Outros trabalhos realizados no âmbito da Rede Latino-Americana de Estudos sobre Trabalho Docente (REDESTRADO) têm apontado para a crescente complexidade do exercício da profissão, destacando-se, entre outros aspetos, uma maior intensificação do trabalho docente e as lógicas gerencialistas que têm tido repercussões no modo de ser e de estar no ensino (veja-se, a título de exemplo, Feldfeber, 2007; Oliveira, 2007; Assaél, 2008; Hypolito; Vieira; Pizzi, 2009).

É escopo deste artigo identificar e analisar os discursos que têm marcado o debate sobre o profissionalismo docente, procurando perceber as suas implicações sobretudo ao nível das identidades dos professores e da (re)construção da profissão docente, no intuito de sintetizar as principais tendências e pontos de discussão na literatura existente nesse domínio.

\section{CONCEPÇÕES DE PROFISSIONALISMO: CARACTERÍSTICAS E DIMENSÕES DE ANÁLISE}

O debate sobre as características essenciais de uma ocupação, para que possa ser designada de "profissão", sobretudo numa perspetiva normativa e sociológica, 
tem sido amplamente desenvolvido, muitas vezes, associado, no caso do ensino, a alguma discussão e até controvérsia (veja-se, a título de exemplo, Etzioni, 1969; Day, 2001; Gewirtzet al.,2009a; Evetts, 2009; Goodwin, 2012). De acordo com uma visão clássica ou sociológica, uma profissão inclui um conhecimento-base especializado (cultura técnica), uma formação específica prolongada, um compromisso para com os clientes e suas necessidades (ética de serviço), um controlo colegial (e não burocrático e externo) no que diz respeito à formação e ao recrutamento dos seus membros (autorregulação) (Hargreaves; Goodson, 1996) e ainda um controlo colegial sobre as práticas e padrões profissionais (autonomia profissional) e uma forte identidade coletiva (compromisso profissional) (Larson, 1977; Talbert; McLaughlin, 1996).

No campo educacional, a literatura sobre essa temática tem procurado analisar o ensino de acordo com o que Whitty (2000, p. 282) descreve como "visão normativa do que significa ser um profissional” à luz das profissões clássicas, como medicina e direito. Em virtude de suas características intrínsecas (e historicamente construídas), nomeadamente o isolamento da sala de aula que impede a construção de uma cultura comum e partilhada pelos professores e a falta de autonomia e controlo sobre os padrões profissionais, o ensino não responde aos critérios de uma profissão, num sentido tradicional, sendo, por isso, designado de semiprofissão (Etzioni, 1969; Gimeno, 1991). ${ }^{1}$

Tradicionalmente, no caso dos professores, a reivindicação tem sido a de que são "profissionais", o que surge associado à percepção de que sua formação lhes faculta o domínio do conhecimento especializado da disciplina, da pedagogia e dos alunos, ao mesmo tempo em que sua posição enquanto professores lhes confere certo grau de autonomia (Day, 2001). Assim, o uso do seu juízo discricionário na tomada de decisões na sala de aula tem sido considerado o terreno-chave no qual os professores são capazes de exercer autonomia, ou ainda, como afirma Freitas (1995), o currículo surge, nesse caso, como a "sede da autonomia" dos professores e, por conseguinte, o "espaço privilegiado" da (re)construção do seu profissionalismo docente.

Outros autores, porém, argumentam que o debate sobre se o ensino é ou não uma profissão deve ser entendido à luz das chamadas caring professions, tais como serviço social e enfermagem (Hargreaves; Goodson, 1996), com base no pressuposto de que a visão mais convencional ou clássica do que significa ser profissional não tem em consideração as características intrínsecas e peculiares do ensino (nomeadamente as suas dimensões pessoal, moral, emocional e social). Nesse contexto, Imbernón (1994) sustenta que a perspetiva clássica se tornou obsoleta, não sendo, por isso,

1 Nessa discussão, advoga-se que há ocupações que não são “verdadeiras” profissões, num continuum que vai de uma ocupação, passando pela semiprofissão até à profissão (Etzioni,1969). Nessa conceptualização, as ocupações sociais detentoras de uma profissionalidade fraca ou incompleta (tais como ensino, enfermagem e serviço social) são entendidas como semiprofissões porque implicariam, entre outros aspetos, uma formação curta, baixos índices de status, baixa especialização do campo de conhecimentos e uma autonomia débil perante a tutela e o controlo social, sendo perspetivadas à luz dos critérios normativos das profissões liberais, ditas profissões de pleno direito, tais como medicina e direito. 
válida para analisar a natureza profissional do ensino, sugerindo que esta visão estática e determinista deve dar lugar a uma visão mais dinâmica e multidimensional de modo a compreender mais profundamente a cultura profissional de uma dada ocupação. A mesma posição é assumida por Power (2008) e Whitty (2008), para quem as profissões se têm desenvolvido de diferentes modos ao longo dos tempos, com implicações ao nível da (re)defnição do seu profissionalismo.

Aliados à controvérsia e complexidade dessa discussão estão os conceitos de profissionalidade, profissionalismo e profissionalização. ${ }^{2}$ A profissionalização encontra-se associada ao projeto ou processo político ou social (ou ainda individual) através do qual uma determinada ocupação (ou indivíduo) procura reconhecimento como profissão (ou como profissional); o profissionalismo diz respeito à natureza e qualidade do trabalho das pessoas, neste caso, dos professores (Sockett, 1993; Imbernón, 1994; Hargreaves; Goodson, 1996; Carlgren, 1999; Hargreaves, 2001).

Essa distinção foi corroborada por um conjunto de professores que participaram numa investigação realizada em Inglaterra e que pretendia analisar a forma como a introdução do currículo nacional tinha afetado seu profissionalismo docente no país. Os resultados apontaram para uma distinção entre "ser um profissional" e "comportar-se profissionalmente", isto é, entre questões de estatuto e reconhecimento público e aspetos associados à ética de serviço e dedicação, respetivamente (Helsby, 1995).

Por seu turno, a profissionalidade refere-se ao conjunto de características essenciais, conhecimentos, destrezas, atitudes e valores específicos de uma dada profissão (Estrela, 2001; Hoyle, 1974; Gimeno, 1991; Imbernón, 1994), ou seja, nas palavras de Whitty (2000, p. 284), “o conteúdo do profissionalismo docente”. É de referir ainda que o profissionalismo, enquanto natureza e qualidade da prática, surge associado ao ideal de serviço e a aspetos de caráter ético e deontológico (Carlgren, 1999; Estrela, 2001; Sockett, 1993). Nesse sentido, partindo da distinção entre estatuto (profissionalização) e prática (profissionalismo), Sockett (1993) distingue quatro dimensões do profissionalismo docente: a) comunidade profissional - tipos de relacionamento dentro das instituições e departamentos em que os professores trabalham; b) conhecimento especializado - conhecimento, visão e perspetivas; c) prestação de contas profissional - obrigação moral para com os alunos e o público; e d) ideal de serviço profissional - intrínseco ao propósito moral do ensino associado ao compromisso para com o bem-estar (e desenvolvimento) dos alunos.

Entender o profissionalismo docente, tratando-se de um conceito social e culturalmente construído (Helsby, 1995), e portanto em permanente transformação, implica situá-lo num dado contexto, o que pressupõe a consideração de diferentes "vozes" e "perspetivas" que se fundamentam em distintas leituras e interpretações

2 Para uma análise mais profunda desses conceitos, e de outros com eles relacionados, ver Hargreaves e Goodson (1996); Hargreaves (1994); Hoyle (1995); Mendes (1996); Hargreaves (2000); Estrela (2001); Flores (2004); Crook (2008); Hoyle e Wallace (2009); e Gewirtz, Mahony, Hextall e Cribb (2009b). 
do mesmo fenómeno ${ }^{3}$ (Hargreaves, 2000; Helsby, 2000). Estudos empíricos têm demonstrado as ambiguidades e ambivalências no entendimento e na experiência do profissionalismo docente (ver, por exemplo, Flores, 2003, 2005), uma vez que se trata de um campo controverso, que depende de um conjunto de fatores, coexistindo distintos discursos que dão forma e legitimam modos de conceber e operacionalizar o profissionalismo docente (Sachs, 2012). Assim, a análise do profissionalismo docente (e o modo como este tem sido afetado ao longo dos tempos) requer não só a compreensão do trabalho dos professores e do modo como estes se veem enquanto profissionais (e como os outros os veem), como também a consideração do contexto - social, político e cultural - em que se inscreve, dado que se trata de um conceito que não é estático, mas antes dinâmico e contextualizado.

\section{DO PROFISSIONALISMO CLÁSSICO AO “NOVO” PROFISSIONALISMO}

Um dos primeiros autores que procurou clarificar a natureza do trabalho dos professores foi Hoyle (1980, p. 49), ao estabelecer a distinção entre o profissional restrito e o profissional amplo. Como refere o autor:

Por profissionalidade restrita, refiro-me a uma profissionalidade intuitiva, centrada na sala de aula e baseada na experiência em detrimento da teoria. Nesta concepção, o bom profissional é sensível ao desenvolvimento de cada aluno, é um professor criativo e um hábil gestor da aula. Não concede importância à teoria, não compara o seu trabalho com o de outros, nem tende a compreender as atividades da sala de aula num contexto mais alargado, valorizando a sua autonomia na sala de aula.

O profissional amplo, por sua vez, preocupa-se em inserir o seu ensino na sala de aula num contexto educacional mais alargado, comparando o seu trabalho com o de outros, avaliando, de forma sistemática, o seu próprio trabalho e colaborando com outros professores. Ao contrário do profissional restrito, interessa-se pela teoria e pelos desenvolvimentos educacionais em curso. Portanto, lê livros e revistas educacionais, envolve-se em várias atividades profissionais e preocupa-se em promover o seu próprio desenvolvimento profissional através de um trabalho contínuo. Encara o ensino como uma atividade racional capaz de ser melhorada através da investigação e de atividades formativas, particularmente aquelas que implicam um estudo extenso. (idem, ibidem, grifos do original)

Essa distinção está ultrapassada (Day, 2001) e não tem em conta as dimensões atuais da profissão docente nem o modo como esta tem sido desafiada perante as mudanças e exigências sociais, políticas e culturais, com implicações no trabalho das escolas e dos professores. Para o mesmo autor, a noção de Lawrence Stenhouse

3 Para uma análise da evolução do conceito de profissionalismo, veja-se Evetts (2009). Essa autora inglesa analisa três interpretações contrastantes de profissionalismo: como valor ocupacional; como ideologia; e como discurso de mudança ocupacional e de controlo gerencialista. 
(1975, p. 144) sobre as características reflexivas dos profissionais que demonstram "uma capacidade para o desenvolvimento profissional autónomo através do estudo individual sistemático, através do estudo do trabalho de outros professores e através do questionamento e verificação de teorias com base em procedimentos de investigação na sala de aula" caracteriza, com mais acuidade e relevância, o trabalho dos professores, sobretudo quando integra a reflexão sobre as condições e contextos políticos que afetam a qualidade do ensino e da aprendizagem.

Hargreaves e Goodson (1996) distinguiram, na literatura desse domínio, cinco discursos de profissionalismo, que se sobrepõem em alguns aspetos. $\mathrm{O}$ profissionalismo clássico, em que o ensino é comparado com as profissões convencionais/liberais (tais como medicina e direito), reside na tentativa de assimilação de condutas e códigos ético-deontológicos predeterminados e controlados pelo próprio corpo de profissionais. Nesse caso, o trabalho é desenvolvido por meio de um forte sentimento ético da sua função no sentido da satisfação das necessidades dos clientes/alunos e de outros agentes educativos. O professor é visto como um especialista numa determinada área (destacando-se o rigor científico e técnico na transmissão de certezas científicas).

Por seu turno, o profissionalismo prático enfatiza a experiência e o saber prático, construído individualmente por cada professor, com base na experiência e nas rotinas (em detrimento do saber técnico). Nesse caso, o profissionalismo é marcado pela experiência e pelo conhecimento prático e desenvolve-se no contexto da sala de aula - espaço de trabalho do professor, que é visto como profissional prático, destacando-se, ao mesmo tempo, o conhecimento prático que o professor vai construindo e o uso do seu juízo discricionário.

Por oposição a esses dois tipos de profissionalismo, Hargreaves e Goodson (1996) identificam os profissionalismos flexível, alargado e complexo, os quais incluem, contrariamente ao clássico e prático, uma visão mais ampla do processo educativo, na medida em que os professores se libertam da transmissão e da exigência de comportamentos predefinidos, alargando seu espaço de ação para além da sala de aula e assumindo um papel que lhes exige o desenvolvimento de capacidades como a resolução de problemas, a comunicação, o desenvolvimento profissional contínuo etc.

Assim, no profissionalismo flexível, o professor assume-se como um profissional de contexto, quebrando-se o isolamento do professor, uma vez que este recorre ao trabalho conjunto com os colegas (para fortalecer opiniões e ações profissionais), o que pressupõe o desenvolvimento de um trabalho integrado e plural produzido pelo conjunto de profissionais de uma dada organização (não se circunscrevendo, portanto, apenas ao espaço da sala de aula). Essa concepção implica, assim, um trabalho colegial, e não isolado, a partilha de saberes profissionais (no contexto de culturas colaborativas), manifestando-se a flexibilidade no grau de colaboração existente nas ações locais desenvolvidas na escola. No entanto, tal como advertem os autores, nesse caso, pode correr-se o risco de aumentar a fragmentação e insularidade do trabalho dos professores, pois a sua ação depende dos contextos em que trabalham.

Por sua vez, o profissionalismo alargado, que os autores também denominam de "novo profissionalismo", implica a consideração do contexto educacional 
mais amplo (organização educativa) - e não apenas a sala de aula -, a negociação de papéis e responsabilidades com diversos intervenientes no processo educativo e uma maior amplitude de papéis, o que conduz a formas de trabalho colaborativo. Nesse contexto, o professor é visto como profissional autónomo (integrando a sua prática, preocupando-se com as teorias educacionais, com a formação contínua, incluindo o trabalho com os outros etc.).

Finalmente, o profissionalismo complexo remete para os paradoxos que marcam a profissão num contexto de crescente complexidade (e desvalorização social da profissão), associada a uma maior exigência e diversidade de alunos. O papel do professor surge situado nas esferas política e social, e o seu comportamento intencional é influenciado pela organização política e pelo processo de socialização profissional.

Hargreaves e Goodson (1996, p. 20-21) propõem, assim, sete princípios para definir o profissionalismo docente:

1. Crescentes oportunidades e maior responsabilidade de usar um juízo discricionário acerca das problemáticas do ensino, do currículo e da atenção que afeta os alunos;

2. Oportunidades e expetativas para se comprometerem com os propósitos morais e sociais, valorizando aquilo que os professores ensinam, juntamente com os principais conteúdos curriculares e a avaliação aos quais estes propósitos estão inerentes;

3. Comprometimento para com o trabalho com colegas em culturas de colaboração, de ajuda e apoio, como uma forma de usar os conhecimentos partilhados para resolver problemas atuais da prática profissional, em vez de realizarem um trabalho conjunto como um instrumento de motivação para implementar as diretrizes externas (decididas por outros);

4. A heteronomia ocupacional em vez da autonomia autoprotetora, em que os professores trabalham com autoridade, mas, ao mesmo tempo, abertamente e de uma forma colaborativa com outros parceiros na comunidade (especialmente os pais e os próprios estudantes), que desempenham um papel importante na aprendizagem dos alunos;

5. Um comprometimento para com o cuidado/atenção e não unicamente um serviço anódino para com os alunos. Sendo assim, o profissionalismo deve admitir e adotar tanto a dimensão emocional, como a cognitiva do ensino, e também reconhecer as competências e disposições que são essenciais para um cuidado/atenção dedicado e eficaz;

6. Uma investigação orientada para o $E u$ e um esforço em relação a uma aprendizagem contínua relacionada com os conhecimentos de cada um e com as práticas standard, em vez de seguir as obrigações debilitadoras das intermináveis mudanças exigidas por outros (frequentemente sob a forma de uma aprendizagem contínua ou de melhorias a introduzir no sistema de ensino); 
7. A criação e o reconhecimento de tarefas de elevada complexidade com níveis de estatuto e recompensa apropriados.

Por seu turno, David Hargreaves descreve, nos anos 1990, a emergência daquilo que o autor designa de novo profissionalismo (no caso da Inglaterra e do País de Gales), em resultado da "síntese do desenvolvimento profissional e institucional" (1994, p. 423). Nas suas próprias palavras, esse novo profissionalismo implica

um movimento para além da autoridade e autonomia tradicional do professor no sentido de novas formas de relacionamento entre colegas, com os alunos e com os pais. Estas relações estão a tornar-se cada vez mais próximas, mais intensas e colaborativas, envolvendo uma negociação de papéis e de responsabilidades mais explícita”. (idem, p. 424)

Esse movimento resulta do alargamento do trabalho dos professores para além da sala de aula para envolver toda a escola em que as prioridades educativas, o planeamento e implementação do currículo e as questões de progressão e de continuidade dos alunos requerem uma maior coordenação por parte dos professores. Por outras palavras, o novo profissionalismo, por oposição ao velho profissionalismo, inclui, entre outros aspetos, uma mudança do individualismo para a colaboração, das hierarquias para as equipas, do processo para o produto, da autoridade para o contrato e da sobrevivência para a emancipação, embora essa perspetiva seja questionada por outros autores (ver, por exemplo, Day, 2001).

Também Hargreaves e Fullan (2012) advertem que o profissionalismo interativo (associado à aprendizagem, ao apoio e à interação em redes e comunidades profissionais de aprendizagem) pode dar lugar a um profissionalismo hiperativo, em que os professores se veem envolvidos em reuniões apressadas no sentido de encontrar soluções rápidas para aumentar os resultados escolares dos alunos.

\section{PROFISSIONALISMO GERENCIALISTA VERSUS PROFISSIONALISMO DEMOCRÁTICO E ATIVISTA}

$\mathrm{Na}$ literatura sobre esse domínio, é incontornável o contributo de Sachs (2003), que propõe a distinção entre o profissionalismo gerencialista e o profissionalismo democrático. O primeiro surge relacionado com a mudança organizacional, com imperativos ligados a uma maior prestação de contas e com questões de eficiência e de eficácia. De modo geral, existem duas características que marcam esse tipo de profissionalismo: a gestão eficiente resolve qualquer problema, e as práticas usadas no setor privado são aplicáveis ao setor público, o que aparece associado aos valores universais do gerencialismo (nomeadamente a consideração de que a gestão é intrinsecamente boa e de que os gestores devem ter margem de autonomia para gerir e os outros grupos devem aceitar a sua autoridade). Essas questões podem ser vistas na burocracia no ensino e em algumas práticas de gestão nas escolas, muitas vezes, associadas a medidas políticas que advogam a descentralização e que levam à emergência desse discurso gerencialista (através, por exemplo, da prestação de contas, de resultados mensuráveis, de rankings etc.). 
Nesse contexto, o profissional responde a metas pré-especificadas externamente, gere bem um conjunto de alunos e documenta os seus resultados para efeitos de prestação pública de contas. Assim, o bom profissional é aquele que responde aos critérios de sucesso preconizados, ou seja, o que trabalha de forma eficaz e eficiente para ir ao encontro dos critérios estandardizados definidos para os alunos, para os professores e para as escolas (idem).

Contrariamente, o profissionalismo democrático procura desmistificar o trabalho profissional e construir alianças entre professores e outros agentes, enfatizando a ação colaborativa e cooperativa (idem). O professor surge com responsabilidades mais amplas, para além da sala de aula, incluindo o contributo para a escola, para o sistema educativo, para a comunidade e para os alunos, bem como responsabilidades coletivas enquanto profissão, com vista à construção de uma sociedade mais justa $\mathrm{e}$ democrática (através, por exemplo, da investigação, da inovação etc.).

A esse propósito, Sachs (idem) identifica duas formas antagónicas de identidade profissional: a empresarial e a ativista. A primeira surge associada a professores eficientes, responsáveis e responsabilizáveis, que demonstram certa obediência aos imperativos políticos impostos a partir do exterior, apresentando um ensino de qualidade que é avaliado mediante um conjunto de indicadores de competência, definido externamente. De modo geral, essa identidade é individualista, competitiva, controladora e reguladora, definida externamente e orientada por e para os padrões. $\mathrm{Na}$ segunda identidade, que se baseia na crença na importância da mobilização dos professores para melhorar as condições de aprendizagem dos alunos, os professores preocupam-se sobretudo em criar e desenvolver padrões e processos de ensino que possam proporcionar aos alunos experiências democráticas (idem). Segundo a autora, a primeira resulta das agendas de performatividade, enquanto a segunda parece estar orientada para a investigação, para salas de aula colaborativas e para escolas onde o ensino está intimamente ligado a amplos valores e ideais da sociedade e onde os objetivos do ensino e da aprendizagem transcendem o instrumentalismo de algumas reformas educativas.

Assim, Sachs (idem) identifica cinco valores centrais que constituem "os fundamentos de uma abordagem pró-ativa e responsável do profissionalismo”:

1. Aprendizagem - em que os professores são encarados como aprendentes, individualmente, com os seus colegas e alunos;

2. Participação-em que os professores se perspetivam como agentes ativos nos seus próprios mundos profissionais;

3. Colaboração - em que a colegialidade é exercida dentro e entre comunidades internas e externas;

4. Cooperação - através da qual os professores desenvolvem uma linguagem comum e a tecnologia para documentar e discutir as suas práticas bem como os seus resultados;

5. Ativismo-em que os professores se envolvem publicamente em questões relacionadas, direta ou indiretamente, com a educação e com a escolaridade, enquanto parte integrante dos seus propósitos morais (Sachs, 2000). 


\section{DISCURSOS E CONCEPÇÕES ALTERNATIVAS DE PROFISSIONALISMO DOCENTE}

De modo geral, é possível identificar na literatura desse domínio duas perspetivas opostas. Se, por um lado, existem autores que associam as transformações no ensino e no modo de encarar o trabalho dos professores a formas de desqualificação (e desprofissionalização) (Gimeno, 1991; Imbernón, 1994; Smyth, 1995), outros referem-se a tendências que apontam para novas formas de re-profissionalização dos docentes (Hargreaves, 1994; McCulloch; Helsby; Knight, 2000). Por outras palavras, a existência de tarefas mais amplas para os professores, a maior complexidade das funções que têm de desempenhar, o juízo mais sofisticado que se lhes exige e a tomada de decisão coletiva apontam para formas de reprofissionalização, enquanto a tendência para uma formação mais pragmática, a redução na tomada de decisão sobre objetivos e propósitos de ensino e a maior dependência em termos de resultados de aprendizagem pré-especificados associam-se a uma lógica de desprofissionalização (Hargreaves; Goodson, 1996).

Mais recentemente, outros autores têm procurado ultrapassar essa perspetiva binária ou dualista (Cunningham, 2008; Gewirtz et al., 2009b). Gewirtz et al. (2009a) argumentam que, para entender o profissionalismo docente, é necessário recorrer a concepções plurais que compreendam todos os elementos numa perspetiva dialética e integradora, incluindo não só uma preocupação com os padrões e questões éticas ("fazer bem o trabalho"), mas também os discursos que legitimam e reproduzem formas particulares de identidade, poder e in/exclusão, mantendo, ao mesmo tempo, as ideias de profissão e de "profissionalismo" em interação.

Defende-se, desse modo, que é possível discutir o que é um bom professor e como melhorar o ensino, na linha do que Friedson (2001) denominou de terceira lógica de análise do profissionalismo docente na sua complexidade e controvérsia. Entre outros aspetos, Friedson (idem) destaca os níveis de controlo das condições e das condutas do trabalho por parte dos profissionais, em que a confiança constitui uma componente essencial dos modos de coordenação profissionais, componente esta que inclui um contrato entre estes e a sociedade mais ampla, a que Fitzgerald (2010) também faz referência a propósito da avaliação do desempenho docente no contexto neozelandês. Nesse sentido, o profissionalismo é, ao mesmo tempo, um regime de controlo e uma ideologia, na medida em que os profissionais precisam de certo grau de poder social e autonomia coletiva, e de demonstrar que se pode confiar neles (Friedson, 2001).

Gewirtz et al. (2009a) advogam a necessidade de olhar para o profissionalismo docente numa perspetiva idealista e crítica, incluindo um modo de coordenação social e um conjunto de virtudes ocupacionais. Barnett (2008), por seu turno, defende um profissionalismo crítico numa era da supercomplexidade, sublinhando a importância de contemplar (e de questionar) os múltiplos discursos existentes nesse campo.

A esse propósito, e partindo da análise do contexto inglês, Whitty (2008) distingue quatro modos de profissionalismo docente: a) tradicional (que o autor associa à autonomia dos professores no que se refere não só ao como, mas também 
ao que ensinar, no período considerado como a idade de ouro da autonomia docente, nomeadamente desde a década de 1950 até a década de 1970 do século passado); b) gerencialista (visível na cada vez maior especificação do que os professores devem fazer nas escolas e nas salas de aula, numa lógica de prestação de contas); c) colaborativo (numa perspetiva de trabalho colaborativo entre os múltiplos atores educativos, associados à ideia da escola "a tempo inteiro", que proporciona apoio ao estudo, oportunidades de aprendizagem para os pais etc., o que implica que os professores passem a trabalhar - e a colaborar - com outros profissionais, por exemplo, profissionais da saúde, assistentes sociais, psicólogos, terapeutas da fala etc.); e d) democrático (que implica maior sensibilidade em relação a um vasto conjunto de agentes educativos, desmistificando o trabalho do professor e forjando alianças entre os professores e outros - nomeadamente aqueles a quem não é dada voz - por exemplo, alunos, pais, membros da comunidade mais vasta, com vista à construção de um sistema educativo mais democrático).

Esses dois últimos modos de profissionalismo, o colaborativo e o democrático, podem, segundo Whitty (2008), oferecer melhores possibilidades de construção da profissão docente do que o profissionalismo tradicional, proporcionando aos professores novas oportunidades profissionais para apoiar a aprendizagem dos alunos e identificando o conhecimento especializado dos docentes, o qual tem de ser transmitido e disseminado de modos diferentes em contextos colaborativos.

Nesse âmbito e para uma melhor compreensão do profissionalismo docente, Evetts (2009, p. 23) distingue dois tipos ideais: o profissionalismo organizacional (ou profissionalismo "a partir de cima") e o profissionalismo ocupacional (ou profissionalismo "a partir de dentro"). O primeiro caracteriza-se por

uma crescente estandardização dos procedimentos e práticas profissionais e controlo gerencialista, baseando-se em formas externas de regulação e medidas de prestação de contas tais como o estabelecimento de metas e a revisão/avaliação do desempenho. (idem, ibidem)

\section{O segundo}

incorpora uma autoridade colegial [...] baseia-se na autonomia, no juízo discricionário e na avaliação pelos práticos. [...] O controlo é operacionalizado pelos próprios práticos que se orientam por códigos de ética profissional que são monitorizados por entidades e associações profissionais. (idem, ibidem)

Na prática, essas duas formas de profissionalismo coexistem, embora seja necessário analisar o equilíbrio entre elas em distintos contextos e práticas profissionais.

Importa ainda convocar a esse propósito o trabalho de Reeves (2009), que identifica três modos discursivos na forma de entender o profissionalismo docente: a) uma concepção restrita burocrático-profissional em que se espera que os professores funcionem como especialistas nas suas salas de aula, mas trabalhando em estruturas burocráticas; b) uma concepção gerencialista em que os professores são vistos como "operacionais", que são supervisionados de perto e seguidores de regras; e c) um "novo" profissionalismo que se baseia nas ideias de colaboração, partilha 
de conhecimento e de "prática centrada nos alunos". As tensões e conflitos que necessariamente se instalam entre esses discursos de profissionalismo permitem, segundo Reeves (idem), criar um "espaço" que os professores poderão usar para forjar um profissionalismo revitalizado e mais amplo.

Por seu turno, Gewirtz et al. (2009a) aludem à mudança discursiva no campo do profissionalismo docente, a que associam a contradição das políticas de regulação e de estandardização, por um lado, e de devolução e diversidade, por outro, traduzindo-se em mudanças complexas e irregulares das identidades dos professores, dos seus papéis e das suas vidas profissionais.

Como destaca ainda Evetts (2009), as noções de profissão e de profissionalismo encerram um paradoxo, na medida em que são cada vez mais usadas nos contextos e nos discursos das sociedades modernas, ao mesmo tempo em que as condições de confiança, juízo discricionário e competência, conceitos historicamente associados à ideia de prática profissional, estão a ser objeto de questionamento e de mudança. Para Sachs e Mockler (2012), a ênfase das políticas atuais em resultados mensuráveis está associada à prevalência das "culturas de performatividade", orientadas para a regulação e medição, o que conduz a uma perspetiva redutora de ensino e de aprendizagem, a um ambiente de desconfiança e a um declínio da autonomia docente.

Com efeito, as mudanças nos contextos políticos e sociais do ensino têm tido implicações substantivas nas subjetividades dos professores e nas concepções de profissionalismo docente. Como reconhecem Day e Sachs (2004, p. 5), as reformas dos últimos anos levaram ao desenvolvimento de um conjunto de paradoxos sobre a natureza do ensino enquanto profissão, pois se, por um lado, se advoga a autonomia na profissão docente, por outro, "existe uma cada vez maior vigilância do seu trabalho por parte dos políticos e da comunidade numa lógica de prestação de contas através dos standards e de rituais de verificação"; se se tende a reconhecer a complexidade e a exigência inerente à mudança das práticas de ensino, por outro lado, os recursos disponibilizados aos professores para sua aprendizagem e seu desenvolvimento profissionais são reduzidos; e se se defende a necessidade de um maior profissionalismo docente reinventando a identidade profissional dos professores, ao mesmo tempo, a evidência aponta para o facto de os professores estarem a ser desprofissionalizados e o seu trabalho intensificado, como resultado do currículo imposto externamente e de sistemas de monitorização, avaliação e supervisão, tornando o ato educativo cada vez mais complexo.

Em trabalho também recente, Nóvoa (2013) discute a distância entre os discursos sobre os professores e as tensões e os dilemas que a profissão docente enfrenta. O mesmo autor chama atenção para a necessidade de construir a profissão docente "a partir de dentro", sublinhando o sentido do conhecimento profissional através da reflexão sobre a atividade e a experiência pedagógica e a ênfase nas práticas colaborativas como modos de organização da profissão.

Assim, é fundamental alargar o âmbito de análise do profissionalismo docente no sentido de incluir o questionamento e a desmistificação das tensões, contradições e dos paradoxos que caracterizam a profissão docente (Flores, 2011, 2012) e que repercutem nas identidades profissionais dos professores. 


\section{CONSIDERAÇÕES FINAIS}

Neste texto procurámos sintetizar algumas tendências e reflexões a propósito das concepções de profissionalismo docente existentes na literatura. A análise do profissionalismo docente no quadro atual implica a consideração dos múltiplos discursos que têm emergido nesse domínio, sobretudo aqueles que se associam às chamadas "culturas de performatividade" e de prestação de contas (Sachs; Mockler, 2012), no sentido de desvelar as implicações (e as contradições) que lhe estão subjacentes e com repercussões nas identidades profissionais dos professores. Assim, para além do questionamento das políticas e do modo como estas são implementadas, é essencial analisar a forma como elas têm afetado o trabalho das escolas e dos professores, e fundamentalmente o modo como o seu profissionalismo tem sido (re)definido.

Da análise da literatura existente nesse domínio, é possível identificar três ideias-chave. A primeira prende-se com o próprio conceito de profissionalismo docente que, sendo complexo e dinâmico, exige sua problematização e seu questionamento à luz das condições de exercício da profissão e dos contextos sociais, políticos e culturais em que se desenvolve o ensino, superando uma visão mais estática e mais linear que surge, muitas vezes, associada às concepções normativas de profissão.

Uma segunda ideia que ressalta da literatura analisada tem a ver com as tensões e os paradoxos que caracterizam a profissão docente e que, naturalmente, exigem reflexão e análise que contemplem as distintas, e por vezes contraditórias, lógicas que coexistem nos discursos sobre profissionalismo docente. Nesse âmbito, urge, por exemplo, questionar e desvelar as implicações das medidas políticas e dos discursos que thes estão associados, no sentido de compreender o modo como afetam o trabalho dos professores e as suas identidades profissionais, sobretudo ao nível das suas crenças e das suas práticas curriculares. Em particular, é fundamental perceber o modo como as agendas de performatividade e de prestação de contas, que têm marcado as decisões políticas no campo da educação um pouco por todo o mundo, têm afetado o profissionalismo docente, quer ao nível do discurso, quer ao nível da implementação de políticas nas escolas (vide Flores, 2011, 2012), desde aspectos ligados à avaliação do desempenho docente, à governação das escolas, às alterações no currículo escolar, à ênfase crescente na avaliação externa etc.

Uma terceira ideia tem a ver com o papel dos professores na (re)definição do profissionalismo docente. Fazer ouvir a sua voz e valorizar a profissão docente constituem dois aspetos essenciais que urge potenciar no sentido de questionar as implicações das decisões políticas no ensino e de construir um profissionalismo interativo e renovado. A esse propósito, Sachs (2012) faz um apelo à ação que passa pelo desenvolvimento da profissão docente em torno de quatro elementos fundamentais: a) confiança; b) autonomia e estabelecimento de padrões; c) juízo discricionário e tomada decisão; e d) compromisso em relação ao desenvolvimento profissional contínuo.

A mesma autora, reconhecendo que o trabalho dos professores é exigente do ponto de vista intelectual, emocional e político, defende uma visão de ensino enquanto profissão que se representa a si própria, com base em um conjunto de valores e em um conhecimento-base, num quadro de confiança, valorização e respeito. Nesse sentido, e como dissemos noutro lugar, "a participação e a agência dos professores e os seus 
propósitos morais assumem uma importância vital", pois "o modo como entendem os seus papéis e as suas tarefas e a natureza do próprio ensino nos contextos em que trabalham - o seu profissionalismo - é vital para o sucesso da mudança e para a melhoria da qualidade do ensino e da aprendizagem nas escolas" (Flores, 2011, p. 182).

Sachs e Mockler (2012) encaram as "culturas de performatividade" ao mesmo tempo como uma ameaça e uma oportunidade, e apresentam uma alternativa à lógica de regulação e de medição, traduzida naquilo que as autoras designam de "perspetiva de desenvolvimento", que procura conciliar os interesses dos vários agentes educativos (comunidades, professores, pais, alunos) e em que os padrões do ensino decorrem da própria profissão e da ação coletiva. Essa perspetiva procura "estabelecer um equilíbrio entre a prestação de contas imposta externamente e as necessidades de desenvolvimento dos professores" (idem, p. 36).

Também para Ben-Peretz (2012), os efeitos da vigilância externa, da regulação e da lógica de medição ampliaram os dilemas dos professores enquanto educadores profissionais e intérpretes das políticas educativas, advogando um equilíbrio entre a prestação de contas e a autonomia profissional no sentido de adaptar as políticas de prestação de contas ao seu próprio contexto. A esse propósito, Lo (2012, p. 16) defende que "a profissão docente deve procurar renovar o seu profissionalismo face à adversidade através de uma postura ativista, promovendo valores essenciais e transformando identidades".

Assim, as alternativas aos cenários mais pessimistas que decorrem das políticas atuais no campo da educação passam por um maior ativismo por parte dos professores (mas também de outros interessados na educação) tendo como lema central a defesa e o reconhecimento do ensino na sua multidimensionalidade e complexidade com vista à (re)construção do profissionalismo "a partir de dentro", numa perspetiva de valorização da profissão docente em contextos cada vez mais desafiadores.

\section{REFERÊNCIAS}

Assaél, Jenny Budnik. Políticas educativas y trabajo docente en Chile. In: Seminário Reestrado - nuevas regulaciones en América Latina, 7., 2008, Buenos Aires. Anais... Buenos Aires: Universidade de Buenos Aires, 2008. p. 1-27.

Barnett, Ronald. Critical professionalism in an age of supercomplexity. In: Cunningham, Bryan (Org.). Exploring professionalism. Londres: Institute of Education, 2008. p. $190-208$.

Ben-Peretz, Miriam. Accountability vs. Teacher autonomy. An issue of balance. In: DAY, Christopher (Org.). The routledge international handbook of teacher and school development. Londres: Routledge, 2012. p. 57-66.

CArlgren, Ingrid. Professionalism and teachers as designers. Journal of Curriculum Studies, Nova York; Londres: Taylor \& Francis, v. 31, n. 1, p. 43-56, 1999.

Своок, David. Some historical perspectives on professionalism. In: Cunningham, Bryan (Org.). Exploring professionalism. Londres: Institute of Education, 2008. p. 10-27. 
Cunningham, Bryan (Org.). Exploring professionalism. Londres: Institute of Education, 2008.

DAY, Christopher. Desenvolvimento profissional de professores. Os desafios da aprendizagem permanente. Porto: Porto Editora, 2001.

. SACHs, Judyth. Professionalism, performativity and empowerment: discourses in the politics, policies and purposes of continuing professional development. In: (Orgs.). International handbook on the continuing professional development of teachers. Maindenhead: Open University, 2004. p. 3-32.

Estrela, Maria Teresa. Questões de profissionalidade e profissionalismo docente. In: Teixeira, Manuela (Org.). Ser professor no limiar do século XXI. Porto: ISET, 2001. p. 113-142.

Etzioni, Amitai (Org.). The semi-professions and their organisation. Nova York: Free Press, 1969.

Evetts, Julia. The management of professionalism: a contemporary paradox. In: Gewirtz, Sharon; Mahony, Pat; Hextall, Ian; Cribb, Alan (Orgs.). Changing teacher professionalism. International trends, challenges and ways forward. Londres; Nova York: Routledge, 2009. p. 19-30.

Feldfeber, Myriam. La regulación de la formación y el trabajo docente: un análisis critico de la "agenda educative" en América Latina. Educação Ẽ Sociedade, Campinas: CEDES, v. 28, n. 99, p. 444-465, 2007.

Fitzgerald, Tanya. Supervisão institucionalizada? A gestão do desempenho nas escolas da Nova Zelândia. In: Flores, Maria Assunção (Org.). A avaliação de professores numa perspectiva internacional: sentidos e implicações. Porto: Areal Editores, 2010. p. 65-82. Flores, Maria Assunção. Teacher professionalism in Portugal and Brasil: theory and practice. In: Markea, Georgia G.; Papanikos, Gregory T. (Orgs.). Global issues of education: proceedings from the 5 th International Conference on Education, on may 23-24, Atenas: Institute for Education and Research, 2003. v. 2, p. 235-242.

Dilemas e desafios na formação de professores. In: Moraes, Maria Célia; Pacheco, José Augusto; Evangelista, Maria Olinda (Orgs.). Formação de professores. Perspetivas educacionais e curriculares. Porto: Porto Editora, 2004. p. 127-160.

. Teachers' views on recent curriculum changes: tensions and challenges. The Curriculum Journal, Londres: Taylor \& Francis, v. 16, n. 3, p. 401-413, 2005.

Tendências e tensões no trabalho docente: reflexões a partir da voz dos professores. Perspectiva. Revista do Centro de Ciências da Educação, Florianópolis: NUP/ CED, v. 29, n. 1, p. 161-191, 2011.

.Teachers' work and lives: a european perspective. In: DAY, Christopher (Org.). The routledge international handbook of teacher and school development. Londres: Routledge, 2012. p. 94-107.

Freitas, Cândido Varela de. Caminhos para a descentralização curricular. Colóquio, Educação e Sociedade, Lisboa: Universidade de Lisboa, v. 10, p. 99-118, 1995.

Friedson, Eliot. Professionalism: the third logic. Londres: Polity Press, 2001. 
Gewirtz, Sharon; Mahony, Pat; Hextall, Ian; Cribb, Alan. Policy, professionalism and practice. Understanding and enhancing teachers'work. In: .(Orgs.). Changing teacher professionalism. International trends, challenges and ways forward. Londres; Nova York: Routledge, 2009a. p. 3-16.

. (Orgs.). Changing teacher professionalism. International trends, challenges and ways forward. Londres; Nova York: Routledge, 2009b.

Gimeno, José. Consciência e acção sobre a prática como libertação profissional dos professores. In: NóvoA, António (Org.). Profissão professor. Porto: Porto Editora, 1991. p. 63-92.

Goodwin, A. Lin. Teaching as a profession. Are we there yet? In: DAY, Christopher (Org.). The routledge international handbook of teacher and school development. Londres: Routledge, 2012. p. 44-56.

Hargreaves, Andy. Four ages of professionalism and professional learning. Teachers and Teaching: Theory and Practice, Londres: Taylor \& Francis, v. 6, n. 2, p. 151-182, 2000.

.Teaching as a paradoxical profession: implications for professional development. In: Xochellis, Panagiotis; Papanaoum, Zoi (Orgs.). Continuing teacher education and school development (Symposium Proceedings). Thessaloniki: Department of Education, School of Philosophy AUTH, 2001. p. 26-38.

. Fullan, Michael. Professional capital. Transforming teaching in every school. Londres; Nova York: Routledge, 2012.

Goodson, Ivor. Teachers' professional lives: aspirations and actualities. In: Goodson, Ivor; Hargreaves, Andy (Orgs.). Teachers' professional lives. Londres: Falmer Press, 1996. p. 1-27.

Hargreaves,David.The new professionalism: the synthesis of professional and institutional development. Teaching and Teacher Education, Londres: Taylor \& Francis, v. 10, n. 4, p. 423$-438,1994$.

Helsby, Gill. Teachers' construction of professionalism in england in the 1990's. Journal of Education for Teaching, Londres: Taylor \& Francis, v. 21, n. 3, p. 317-332, 1995.

Multiple truths and contested realities. The changing faces of teacher professionalism in England. In: Day, Christopher; Fernandez, Alicia; Hauge, Trond E.; Molner, Jorunn (Orgs.). The life and work of teachers. International perspectives in changing times. Londres: Falmer Press, 2000. p. 93-108.

Hypolito, Álvaro Moreira; Vieıra, Jarbas Santos; Pizzi, Laura Cristina Vieira. Reestruturação curricular e autointensificação do trabalho docente. Currículo sem fronteiras, [s.1.s.n.], v. 9, n. 2, p. 100-112, 2009.

Hoyle, Eric. Professionality, professsionalism and control in teaching. London Educational Review, Hove: University of London Institute of Education, v. 3, n. 2, p. 13-19, 1974.

Professionalization and de-professionalization in education. In: Hoyle, Eric; Megarry, Jacquetta (Orgs.). World yearbook of education 1980: the professional Development of Teachers. Londres: Kogan Page, 1980. p. 42-56. 
. Teachers as professionals. In: Anderson, Lorin W. (Org.). International encyclopedia of teaching and teacher education. 2. ed. Oxford: Pergamon, 1995. p. 11-15.

. Wallace, Mike. Leadership for professional practice. In: Gewirtz, Sharon; Mahony, Pat; Hextall, Ian; Cribb, Alan (Orgs.). Changing teacher professionalism. International trends, challenges and ways forward. Londres; Nova York: Routledge, 2009.

Imbernón, Francisco. La formación y el desarrollo profesional del profesorado. Hacia una nuvea cultura profesional. Barcelona: Editorial Graó, 1994.

Larson, Magali Sarfatti. The rise of professionalism: a sociological analysis. Berkeley: University of California Press, 1977.

Lo, Leslie Nai Kwai. Introduction. In: DAY, Christopher (Org.). The routledge international handbook of teacher and school development. Londres: Routledge, 2012. p. 13-18.

McCulloch, Gary; Helsby, Gill; Knight, Peter. The politics of professionalism. Teachers and the curriculum. Londres: Continuum, 2000.

Mendes, António Neto. O profissionalismo docente em debate. Aveiro: Fundação João Jacinto de Magalhães, 1996.

NóvoA, António. Teachers: how long until the future? In: Flores, Maria Assunção; Carvalho, Ana Amélia; Ferreira, Fernando Ilídio; Vilaça, Maria Teresa (Orgs.). Back to the future: legacies, continuities and changes in educational policy, practice and research. Rotterdam; Boston; Taipei: Sense Publishers, 2013. p. 29-38.

Oliveira, Dalila Andrade. Política educacional e a reestruturação do trabalho docente: reflexões sobre o contexto latino-americano. Educação E̋ Sociedade, Campinas: CEDES, v. 28 , n. 99 , p. 355-375, 2007.

Power, Sally. The imaginative professional. In: Cunningham, Bryan (Org.). Exploring professionalism. Londres: Institute of Education, 2008.

Reeves, Jenny. Inventing the chartered teacher. In: Gewirtz, Sharon; Mahony, Pat; Hextall, Ian; CRib B, Alan (Orgs.). Changing teacher professionalism. International trends, challenges and ways gorward. Londres; Nova York: Routledge, 2009. p. 106-116. SACHs, Judyth. The activist professional. Journal of Educational Change, Dordrecht: Springer, v. 1, n. 1, p. 77-95, 2000.

The activist teaching profession. Buckigham: Open Unversity Press, 2003.

Teacher professionalism: why are we still talking about it? In: Congresso Anual da Association of Teacher Education in Europe (ATEE), 37., 2012, Eskisehir. Anais... Eskisehir (Turquia): Universidade de Anadolu, 2012. p. 1-20.

Mockler, Nicole. Performance cultures of teaching. Threat or opportunity. In: DAY, Christopher (Org.). The routledge international handbook of teacher and school development. Londres: Routledge, 2012. p. 33-43.

Sмyтн, John. Teachers' work and the labor process of teaching. Central problematics in professional development. In: Guskey, Thomas R.; Huberman, Michael (Orgs.). 
Professional development in education: new paradigms and practices. Nova York: Teachers College Press, 1995. p. 69-91.

Sockeтt, Hugh. The moral base for teacher professionalism. Columbia: Teacher's College Press, 1993.

Stenhouse, Laurence. An introduction to curriculum research and development. Londres: Heinemann Educational Books, 1975.

Talbert, Joan E.; McLaughlin, Milbrey W. Teacher professionalism in local school contexts. In: Goodson, Ivor; Hargreaves, Andy (Orgs.). Teachers' professional lives. Londres: Falmer Press, 1996.

Whiтty, Geoff. Teacher professionalism in new times. Journal of In-Service Education, Londres: Taylor \& Francis, v. 26, n. 2, p. 281-295, 2000.

Changing modes of teacher professionalism: traditional, managerial, collaborative and democratic. In: Cunningham, Bryan (Org.). Exploring professionalism. Londres: Institute of Education, 2008.

\section{SOBRE A AUTORA}

Maria Assunção Flores é doutora em educação pela Universidade de Nottingham (Reino Unido). Professora associada da Universidade do Minho (Portugal).

E-mail: aflores@ie.uminho.pt 
